\title{
Technical Characteristics of a solar geoengineering deployment and implications for governance
}

\author{
Douglas G. MacMartin, ${ }^{1^{*}}$ Peter J. Irvine, ${ }^{2}$ Ben Kravitz, ${ }^{3,4}$ and Joshua B. Horton ${ }^{2}$
}

\begin{abstract}
${ }^{1}$ Sibley School of Mechanical and Aerospace Engineering, Cornell University, Ithaca, NY ${ }^{2}$ School of Engineering and Applied Sciences, Harvard University, Cambridge, MA

${ }^{3}$ Department of Earth and Atmospheric Sciences, Indiana University, Bloomington, IN ${ }^{4}$ Atmospheric Sciences and Global Change Division, Pacific Northwest National Laboratory, Richland, WA
\end{abstract}

*To whom correspondence should be addressed: Sibley School of Mechanical and Aerospace Engineering, Cornell University, 561 Upson Hall, Ithaca, NY 14853, USA. E-mail: dgm224@cornell.edu

\section{Submission to Climate Policy}

\begin{abstract}
Consideration of solar geoengineering as a potential response to climate change will demand complex decisions. These include not only the choice of whether to deploy solar engineering, but decisions regarding how to deploy, and ongoing decision-making throughout deployment. Research on the governance of solar geoengineering to date has primarily engaged only with the question of whether to deploy. We examine the science of solar geoengineering in order to clarify the technical dimensions of decisions about deployment-both strategic and operational-and how these might influence governance considerations, while consciously refraining from making specific recommendations. The focus here is on a hypothetical deployment rather than governance of the research itself. We first consider the complexity surrounding the design of a deployment scheme, in particular the complicated and difficult decision of what its objective(s) would be, given that different choices for how to deploy will lead to different climate outcomes. Next, we discuss the on-going decisions across multiple timescales, from the sub-annual to the multi-decadal. For example, feedback approaches might effectively manage some uncertainties, but would require frequent adjustments to the solar geoengineering deployment in response to observations. Other decisions would be tied to the inherently slow process of detection and attribution of climate effects in the presence of natural variability. Both of these present challenges to decision-making. These considerations point toward particular governance requirements, including an important role for technical experts - with all the challenges that entails.
\end{abstract}


Key Policy Insights

- Decisions about solar geoengineering deployment will be informed not only by political choices, but also by climate science and engineering.

- Design decisions will pertain to the spatial and temporal goals of a climate intervention and strategies for achieving those goals.

- Some uncertainty can be managed through feedback, but this would require frequent operational decisions.

- Some strategic decisions will depend on the detection and attribution of climatic effects from solar geoengineering, which may take decades.

- Governance for solar geoengineering deployment will likely need to incorporate technical expertise for making short-term adjustments to the deployment and conducting attribution analysis, while also slowing down decisions made in response to attribution analysis to avoid hasty choices.
Commented [Ed1]: OK?

Commented [DM2R1]: Better, thanks!

Commented [Ed3]: OK? 


\section{Introduction}

There is increasing awareness of the substantial gap between the amount of mitigation needed to avoid dangerous anthropogenic climate change and current mitigation commitments (Rogelj et al., 2016; Höhne et al, 2017, IPCC, 2018). Solar geoengineering approaches have the potential to provide an additional option for managing the risks of climate change as illustrated qualitatively in Figure 1 (Wigley, 2006; Smith and Rasch 2013, Long and Shepherd, 2014; Sugiyama et al., 2018; MacMartin et al., 2018), with the most frequently discussed option being the addition of aerosols to the stratosphere to reflect some sunlight back to space (Crutzen, 2006; National Academies, 2015). Not enough is currently known to support informed decisions regarding deployment of such approaches (e.g., MacMartin et al., 2016, MacMartin and Kravitz 2019a), but preliminary climate modeling suggests that solar geoengineering in addition to mitigation is likely to reduce many climate risks (e.g., Keith and Irvine, 2016; Irvine et al., 2019).

Deployment of solar geoengineering would have global effects, leading to the question of how one might govern use of these technologies (e.g., Parson, 2013; Parson and Ernst, 2013; Rayner et al., 2013; Bodansky, 2013; Barrett, 2014; Horton and Reynolds, 2016; Reynolds, 2016, Horton et al 2018, Nicholson et al 2018, Horton and Keith 2019). The international community has agreed upon a limit of 1.5 to $2^{\circ} \mathrm{C}$ rise in global mean temperature above preindustrial levels (UNFCCC, 2015), but $1.5^{\circ} \mathrm{C}$ could be surpassed within the next 1-2 decades (IPCC, 2018). This poses some degree of urgency in developing solar geoengineering governance mechanisms, while simultaneously continuing scientific research necessary to assess impacts and risks.

Most of the geoengineering governance literature to date focuses on either the governance of nearer-term research prior to deployment (e.g., Nicholson et al 2018) or on the decision of whether or not to deploy, including different scenarios under which deployment might be considered, and different models for participating in the initial deployment decision. In a recent comprehensive review of the literature, Reynolds (2019) observes that "... little writing has considered the governance needs and potential responses that would arise subsequent to any solar geoengineering deployment." Indeed, we are not aware of any substantive discussions in the governance literature that addresses either the complexity of the decision to deploy solar geoengineering, which is far more than a simple binary yes/no, nor the series of ongoing operational decisions following the start of a deployment.

While the governance literature has generally neglected to examine the technical aspects of deployment decisions up to now, it is nevertheless alert to issues related to "the politics of expertise." Particularly relevant herein, Barrett (2014) recognizes that solar geoengineering would involve more than a single decision, and Parson and Ernst (2013) describe the need for "keeping decision-making linked to scientific understanding ... and protecting scientific deliberations and judgments from political pressures." This reliance on technical expertise has led some to question if solar geoengineering is compatible with democracy (Szerszynski et al 
2013, Hulme 2014), a point countered both by Heyward and Rayner (2015) and by Horton et al (2018). Without a better sense of the content and character of technical decisions, however, it is difficult to fully gauge their political implications for governance of solar geoengineering.

The purpose of this article is to highlight what climate science and engineering have to say about the specifically technical dimensions of the decisions - both operational and strategicthat would need to be made if solar geoengineering were deployed, and to consider the political implications for governance. The lack of substantive considerations of the technical aspects of deployment decisions in the governance literature represents a significant gap that inhibits the type of systematic policy analysis necessary to assess whether and how solar geoengineering should be integrated into the climate policy portfolio. This article aims to begin filling that gap.

\section{(Insert Figure 1)}

Figure 1. Reducing greenhouse gas emissions, combined with future large-scale atmospheric $\mathrm{CO}_{2}$ removal, may lead to long-term climate stabilization with some overshoot of desired temperature targets. One possible scenario for a (temporary and limited) solar geoengineering deployment is as part of an overall strategy to reduce climate risks during the overshoot period. (Figure based on Long and Shepherd, 2014, and reproduced from MacMartin et al., 2018 with permission).

\section{Overview of decisions}

In what follows, we lay out a set of decisions that we suggest may be associated with deploying solar geoengineering and managing ongoing deployment. We then seek to characterize the nature of these decisions. Decisions relating to deployment can be usefully categorized as either more strategic, or more operational, in nature. Strategic decisions, such as whether or not to deploy any form of solar geoengineering, or decisions that affect the distribution of outcomes, will be largely political in nature. In contrast, operational decisions, such as how to adjust deployment in response to observed climatic effects, will be more technical in nature, that is, dependent on scientific and engineering expertise to interpret and implement strategic decisions. Of course, strategic decisions will contain technical elements ("what is technically possible?"), and technical decisions will invariably have political implications ("what are the distributive consequences?").

Many choices would be neither binary nor static. Different design choices for how to deploy solar geoengineering will lead to different projected outcomes. But since outcomes will never exactly match projections, observations made during deployment will then drive subsequent decisions across a wide range of timescales. To understand these choices, it is necessary to consider the characteristics of a well-intentioned deployment in greater detail; one might then hope to structure governance that could enable and encourage such an ideal scenario. Note 
that both Talberg et al (2018) and Sugiyama et al (2018) stress the importance of the scenario in evaluating solar geoengineering. Some of the decisions we consider herein are effectively independent of the scenario (e.g., simply observing that certain decisions must be made), while other decisions we consider are more relevant to an "ideal" well-intentioned scenario, in which decisions are made with the aim to maximize benefits and minimize harms. In discussing how decisions could be made, this paper thus could be viewed in the context of a "strategic conversation" scenario, as introduced by Talberg et al (2018).

Much of the initial climate research into solar geoengineering has been exploratory, e.g., how models respond differently to a decrease in sunlight versus an increase in greenhouse gas (GHG) concentrations. Multiple climate models have simulated an idealized reduction in sunlight (e.g., Kravitz et al., 2013, Irvine et al 2019), and many climate models have simulated the response to a continuous addition of stratospheric sulfate aerosols at some location, typically in the form of $\mathrm{SO}_{2}$ that subsequently oxidizes and forms sulfate aerosols (e.g., Pitari et al., 2014). While informative, it would be a mistake to interpret any of these simulations as describing how the climate would respond to solar geoengineering because they test ad hoc strategies rather than intentionally designed ones. The climate modeling community has recently begun to move beyond these idealized explorations and engage with three characteristics of a hypothetical deployment.

First, the climate response to solar geoengineering will depend on choices that must be made regarding how it is deployed. With stratospheric aerosols, for example, this includes not only the amount of material injected but also the type of aerosol released (Keith et al 2016), as well as the latitudes (Tilmes et al 2017, Dai et al 2018), altitudes (Tilmes et al 2018), and times of year of that injection (Visioni et al 2019). This means that, not only could one aim for more or less global cooling, but one could put more emphasis on, for example, high versus low latitudes, or the Northern versus Southern hemisphere (Kravitz et al., 2016; MacMartin et al., 2017; Kravitz et al., 2017). Regardless of how they are made, choices such as these will influence the distribution of benefits and harms. Within limits, solar geoengineering might be designed to achieve specified outcomes or minimize other effects (MacMartin et al., 2013; Kravitz et al., 2016; MacMartin and Kravitz, 2019b). Here, "design" does not mean specifying a particular institutional architecture for making basic political decisions about solar geoengineering, but rather, planning the precise physical and chemical attributes of a specific solar geoengineering intervention scheme. In this sense, one can only evaluate the climate impacts of a particular design for solar geoengineering deployment rather than solar geoengineering in general, as those impacts are a function of the design. Design decisions for solar geoengineering deployment are strategic in nature, focused on overall goals and approaches for achieving them.

Second, no amount of research will reduce uncertainty to zero, and decisions will inevitably be revisited in light of the observed response of the climate to solar geoengineering interventions. It is in principle possible to manage a solar geoengineering deployment so that at least some 
desired outcomes are maintained despite uncertainty in the climate response (MacMartin et al., 2014a; Kravitz et al., 2014; Kravitz et al., 2016; Kravitz et al., 2017). By “management," we mean making instrumental, operational decisions about modifying details of the approach for a deployment that is already underway. That is, some form of adaptive management (e.g., Holling, 1978; Chris, 2015) is essential.

However, this introduces a third challenge: it may be difficult to confidently detect climate changes due to solar geoengineering, including those predicted to occur (MacMartin et al 2019). How can observed changes be correctly attributed to solar geoengineering in the presence of both natural variability and uncertainty in the response to other human perturbations to the climate system? If an unexpected change in climate is detected and attributed to solar geoengineering, this could lead to revisiting strategic decisions regarding its goals, or even revisiting the choice to deploy.

In what follows, we consider these three characteristics of deployment, along with their corresponding challenges for decision-making.

1. Different ways of deploying will lead to different outcomes (Section 3). Solar geoengineering can be "designed" to achieve a range of different possible climates. Given that, what are the goals for deployment? This is more complex than simply manipulating a "global thermostat;" deployment is not a univariate decision.

2. Some uncertainties can be managed through feedback (Section 4.1). Climate models do not need to be perfect, as the magnitude of the geoengineered-perturbation does not need to be perfectly predicted in advance; it can be adjusted in response to the observed climate - a feedback process. However, this would require frequent updates that may be very hard to realize in a political environment that is usually characterized by slow decision making.

3. Detection and attribution of regional changes will take decades (Section 4.2). There will always be unpredictable weather and climate events, and determining causation with confidence will take time. Thus, in the face of this inevitable uncertainty about the effects of solar geoengineering, extreme patience would be desirable with regard to some decisions.

These last two propositions, associated with the time-scales of evolving decisions, may appear to be contradictory. In reality, there will be a continuum of time-scales associated with different features in the climate response (Section 4.3).

We explicitly avoid any discussion in Sections 3 and 4 regarding how one might design governance to enable decisions. Section 5 concludes with some brief thoughts tying the nature of decisions explicated in the previous sections to the needs of governance. 


\section{Spatial and temporal goals}

Mitigation policy at the global level primarily involves a single decision variable, net GHG emissions. While mitigation involves multiple and complex trade-offs between social, economic and climate outcomes, there are no substantive trade-offs associated directly with climate outcomes: lower emission levels yield less climate damage than do higher emission levels, and as a consequence, a single number such as " $2{ }^{\circ} \mathrm{C}$ " can stand in as a proxy for a wide collection of impacts. That is not true for solar geoengineering.

\section{(Insert Figure 2)}

Figure 2. Illustration of how different choices for solar geoengineering would lead to different outcomes (illustrated here for stratospheric aerosols). The aerosol optical depth (AOD, a measure of how much the stratospheric particles attenuate sunlight reaching the surface) is shown, scaled for a $1 \mathrm{Tg}$ per year injection of $\mathrm{SO}_{2}$, calculated in a fullycoupled chemistry-climate model, for injection at $30^{\circ} \mathrm{S}$ (green), $30^{\circ} \mathrm{N}$ (red) and split equally between $15^{\circ} \mathrm{S}$ and $15^{\circ} \mathrm{N}$ (blue). These choices will result in quite different climate outcomes, allowing some potential to design the deployment to achieve specified goals by choosing some linear combination of these. Figure is based on simulations described by Tilmes et al. (2017).

First, solar geoengineering does not affect the climate the same way that reduced concentrations of atmospheric GHGs would, leading to potentially disparate regional outcomes (e.g., Ricke et al., 2010), and feeding into the well-known concern over "who gets to set the thermostat." However, reality is more complex. The climate response to solar geoengineering will depend on how it is deployed. With stratospheric aerosols, for example, one could choose how much to inject at different latitudes to obtain some influence over climate outcomes (MacMartin et al., 2017; Dai et al., 2018); this is illustrated in Figure 2. By injecting aerosols into one or the other hemisphere, for example, one could influence the relative cooling between hemispheres to minimize shifts in tropical precipitation that could disrupt tropical precipitation patterns (Haywood et al., 2013; Kravitz et al., 2016). By injecting aerosols at higher latitudes, one could put more emphasis on cooling higher rather than lower latitudes. It is unclear as to how many independent degrees of freedom could be achieved, but there are at least these three. Other solar geoengineering approaches, such as marine cloud brightening (brightening low clouds over the ocean by injecting sea salt particles into them; Latham, 1990) might allow more degrees of freedom and effects that are complementary to those of stratospheric aerosols (Boucher et al., 2017). It is thus insufficient to agree only on a target for global mean temperature; a decision to deploy must be based at least implicitly on high-level multivariate goals for the deployment (Kravitz et al., 2016).

The U.N. Framework Convention on Climate Change committed nations to avoiding dangerous anthropogenic interference in the climate system. Over time, this qualitative goal was translated into the quantitative goal of limiting warming to well below $2^{\circ} \mathrm{C}$ (see Article 2 of UNFCCC, 2015). A similar exercise could arrive at multivariate quantitative goals for solar
Commented [Ed5]: Please change as you see fit $-m$ point is that the trade offs are more complex than just two way economics/climate.

Commented [DM6R5]: Great! 
geoengineering. This could be as simple as specifying the desired global mean temperature and maintaining some minimum amount of Arctic sea ice extent, while minimizing shifts in tropical precipitation. More complex multivariate goals could be defined, provided that there is sufficient understanding of the physical relationship between these goals and the available degrees of freedom to use as a basis for design (a non-trivial requirement). The ability to design for multivariate goals could complicate negotiations over solar geoengineering deployment, in that there are more choices to be made, but could also simplify them, as some concerns that lead to conflicting desires may be partially alleviated.

There will still be fundamental trade-offs, and what constitutes the "ideal" climate is not clear. A plausible goal could be to avoid significant change with respect to some baseline climate state (e.g., the climate at the time solar geoengineering is commenced), but trade-offs remain inevitable. A $2^{\circ} \mathrm{C}$ world achieved purely through mitigation will not be the same as a $2^{\circ} \mathrm{C}$ world achieved through less aggressive mitigation and some amount of solar geoengineering. However, with multiple degrees of freedom, solar geoengineering can be designed to make these cases more similar than much of the early research would suggest (Kravitz et al., 2016, 2017, MacMartin and Kravitz 2019b). Nonetheless, there will still be differences between how solar geoengineering affects the climate and how other anthropogenic influences do so, due to the different mechanisms of radiative forcing (though it is not clear today how significant these changes might be).

Importantly, the fact that the entire climate system is coupled puts strong constraints on what is possible with solar geoengineering. Even if we understood the system perfectly, it would not be possible to independently adjust every possible climate outcome, neither choosing different effects at spatially proximate locations, nor simultaneously determining temperature and precipitation outcomes at any location, nor eliminating extreme events, for example.

The temporal aspect to the goal also needs to be defined. If solar geoengineering were ever deployed, there are several reasons to only gradually ramp it up over time rather than immediately demanding a substantial deployment level to cool the planet quickly. This strategy allows possible surprises to be discovered earlier (e.g., Keith and MacMartin, 2015) while the perturbation to the climate system is still relatively small. Furthermore, rapid changes in the perturbation can also lead to unnecessary climate impacts, such as a short-term reduction in monsoonal precipitation due to the differential rate of land versus ocean cooling (e.g., Robock et al., 2013). Thus, for example, in the presence of still-rising atmospheric GHG concentrations, one might choose to maintain conditions as close as possible to the year in which deployment starts, as implied by Figure 1. Other scenarios include limiting only the rate of change of warming (MacMartin et al., 2014b).

A decision to deploy would thus also need to define the initial approach to meet these goals (e.g., how much $\mathrm{SO}_{2}$ to inject per year at which latitudes, and how that is expected to change as a function of time); ideally, it would also articulate what the justification is for concluding that 
that approach would meet the goals, what the projected impact would be on any climate variable not explicitly specified, and an assessment of (and justification for) confidence in projections (MacMartin and Kravitz, 2019a). The analysis needed to support a decision to deploy would thus be a major endeavor, potentially demanding greater efforts than have gone in to the periodic assessments of climate science by the Intergovernmental Panel on Climate Change (IPCC). Climate scientists and engineers can in principle provide this type of information, and indicate what is and is not achievable, but the definition of goals is a policy choice.

\section{Evolving decisions}

No amount of research will reduce the uncertainty in projected impacts to zero. Uncertainty arises due to a variety of sources (e.g., MacMartin et al., 2016). Uncertainty in specific processes, such as aerosol microphysical growth assumptions, or ozone-chemistry reaction rates, might be sufficiently reducible through a combination of better observations after volcanic eruptions (Robock et al., 2013) and small-scale process-level field experiments (Keith et al., 2014; Dykema et al., 2014). However, an experiment to directly measure the climate response - how variables such as regional temperature and precipitation might change in response to solar geoengineering - would require both considerable time and magnitude of change (MacMynowski et al., 2011), making such a test practically equivalent to deployment (Robock et al., 2010, MacMartin and Kravitz, 2019a). Indeed, even early deployment would not likely involve sufficient levels to quickly resolve many uncertainties (MacMartin et al 2019), as described below. Thus, there will always be some residual level of uncertainty in the climate response at the time of a deployment decision. Note, however, that this is also true for climate change - considerable uncertainties persist regarding how anthropogenic emissions have altered the climate despite the substantial changes that have occurred to date.

If it becomes clear during deployment that some outcome is not what was predicted, a choice will be faced as to whether to modify the approach for meeting goals (such as increasing or decreasing the amount of $\mathrm{SO}_{2}$ injected at some latitude), modify the goals themselves (put more or less emphasis on some outcome), or potentially phase-out deployment altogether. Sub-sections 4.1 and 4.2 below consider what these decisions over time might look like. These can pose additional challenges for how to structure international governance either by requiring immediate action, or conversely, by requiring a high degree of patience and consequent longevity of institutions.

While the climate system does not provide any clear separation of time-scales, some structure can be imposed based on how decisions might be made, by dividing the problem into those relatively few high-level climate goals that the intervention is designed to meet, and all of the vast number of other climate system variables that affect humans and ecosystems. For example, if solar geoengineering was intended to maintain global mean temperature at $2^{\circ} \mathrm{C}$, then any sustained period warmer or cooler than that could justify increasing or decreasing the 
amount of solar geoengineering; the sign of the effect this would have on temperature is clear from basic physics. However, the impact on precipitation in some country might, at the time of a deployment decision, be uncertain even in sign; this type of effect would need to be monitored, any observed changes determined to be attributable to the deployment or not, and a decision made as to whether to alter the deployment in response. These two examples yield quite different timescales for decisions.

\subsection{Managing uncertainty through feedback}

No engineered system is perfectly understood. Rather than simply introducing an input and hoping for the best, systems from aircraft flight control to manufacturing plants all rely on feedback: the output is monitored, compared with the desired value, and the inputs slightly adjusted so that over time the output converges to the desired value. One relies on the same fundamental principle every time one drives a car or takes a shower in an unfamiliar place; in an ecosystem context, this is known as adaptive management (Holling, 1978). In the context of earth system management, Schellnhuber and Kropp (1998) term this "geocybernetics." This feedback process compensates for some degree of uncertainty in the strength of the relationship between input and output. Thus, for example, the amount of solar geoengineering required to offset the warming from some amount of $\mathrm{CO}_{2}$ varies from model to model (MacMartin et al., 2015). Following Jarvis and Leedal (2012), MacMartin et al. (2014a) demonstrated the idea of using feedback of the "observed" global mean temperature to adjust the amount of solar radiation reduction in a climate model; Kravitz et al. (2014) then demonstrated that this process was sufficiently robust so that even if the feedback algorithm was tuned using simulations from one climate model, it still yielded the desired outcomes in a second. This idea has been extended to manage multiple climate variables simultaneously (Kravitz et al., 2016), and to do so by adjusting the amount of $\mathrm{SO}_{2}$ injection at multiple latitudes (Kravitz et al., 2017) rather than idealized patterns of solar reduction. In each of these cases, there is a clear physical relationship between the input and output; e.g., increasing the aerosol injection rate decreases temperature, and shifting more of the injection to one hemisphere from the other preferentially cools that hemisphere. However, the exact relationship does not need to be known, and thus some amount of uncertainty can be managed. To successfully implement solar geoengineering to achieve some temperature target, for example, we do not need to know either how much radiative forcing is exerted by a given rate of aerosol injection, or how much the climate cools in response - just that increased injection causes increased cooling.

This capability to manage uncertainty requires the ability to constantly make slight adjustments to the system. Anyone who has impatiently tried to adjust the temperature of a shower knows how difficult the task can be if there is substantial time delay between moving the knob and feeling the resulting change. If one waited for 10 years to see what the effect of solar geoengineering was on the temperature before making any adjustment, then on average that information is now 5 years old, introducing a substantial time delay. It is better to make minor
Commented [Ed12]: Which two examples? This paragraph only has one.

Commented [DM13R12]: I count two... (i) global mean temperature, (ii) regional precipitation

Commented [Ed14]: You tend to use GHG in the paper can we change to GHG here?

Commented [DM15R14]: The reference dealt only with $\mathrm{CO} 2$ which is why I made it specific here... there's actually even more issues that different models have different relative responses to different greenhouse gases that don't want to get into here.

Commented [Ed16]: OK?

Commented [DM17R16]: ok 
adjustments frequently (for example, every year), even if the lack of statistical significance means that one might be reacting to climate variability (and indeed, such an algorithm will always react to and modify climate variability; MacMartin et al., 2014a). If such a feedback process were used in solar geoengineering deployment, the details regarding how much to adjust would be esoteric, although the basic concept is straightforward.

The utility of a rapid decision-making capability is not restricted to managing uncertainty. An additional reason would be if a large volcanic eruption occurred during deployment of stratospheric aerosol geoengineering. One could choose to do nothing different; in this case the decrease in global temperature might still be less than if there were no geoengineering due to nonlinearities in sulfate aerosol microphysics (Laakso et al., 2016). However, it would be wiser to decrease injection immediately - on a time-scale of weeks - to compensate for the increase in stratospheric sulfate from the eruption. Furthermore, an eruption in one hemisphere will preferentially cool that hemisphere, shifting the intertropical convergence zone (ITCZ) towards the opposite hemisphere, and shifting tropical precipitation with it; this can have significant consequences such as Sahelian drought (Haywood et al., 2013). Thus, one might want to rapidly increase the injection of aerosols into the opposite hemisphere to counterbalance the effect of the eruption on tropical precipitation over the ensuing year.

The importance of short time-scale decisions clearly has ramifications for governance, as described in Section 5. However, other decisions may present governance challenges at the opposite end of the spectrum due to the long time-scales involved in detection and attribution of changes not predicted at deployment.

\subsection{Detection and attribution may take decades}

The example given earlier for high-level goals included global mean temperature, Arctic sea ice extent, and tropical precipitation. However, the ultimate goals of reducing climate damages are more complicated and multi-dimensional. Prior to deployment there would presumably be a comprehensive multi-model assessment of the predicted impact of solar geoengineering, not only for high-level goals, but for regional climate shifts, changes in probability of different weather events, and so forth. If models predict that solar geoengineering will increase the likelihood or magnitude of some particular type of extreme weather event, and if such an event does occur, it is reasonable to (at least fractionally) attribute that event to the deployment; this may be useful in compensation schemes, for example (Horton, Parker, and Keith, 2015).

However, there will always be uncertainty in model predictions, and prediction skill will be more limited for some variables than others. This leads to a challenge: acknowledging model uncertainty requires a willingness to learn through observations, while at the same time not responding to every weather event or perceived shift in climate that occurs. Learning where model predictions were meaningfully wrong will take time. Furthermore, even the benefits of deployment will not be immediately apparent. 
If one learns that the deployment is leading to some undesired and unpredicted shift in regional climate (including changes in the magnitude or frequency of some extreme weather events), one could alter the high-level goals; e.g., allow global mean temperature to increase slightly so that less solar geoengineering is required, or change the relative emphasis on high vs lowlatitudes, or introduce additional goals. Indeed, a possible decision would be to terminate the deployment altogether (ideally through a gradual phase-out as was shown by MacMartin et al., $2014 \mathrm{~b}$, to avoid a shock to the system that would occur if solar geoengineering were abruptly terminated).

The challenge with this collective set of decisions, involving every climate variable at any spatial scale, is that the very concept of "climate" that is at the core of either climate change or climate engineering describes long-term multi-decadal characteristics. Over shorter time-scales, there is considerable variability that can mask the response due to solar geoengineering. For example, despite the duration of anthropogenic GHG forced climate change today, while there is no ambiguity regarding the direction of the effect on some metrics like global mean temperature or Arctic sea ice extent, there is still considerable uncertainty in how increased GHGs have affected regional precipitation patterns (Kirtman et al., 2013), and even at the global scale there can be substantial decadal variability in the trend (e.g., the so-called "hiatus" of the early 2000s; e.g., Lewandowsky et al., 2018). Attribution of individual storms or droughts to climate change is improving but remains difficult today (Herring et al., 2019), in part because of insufficient statistics on the probability of rare events. There will always be unusual events; for example, in any single year, one might expect $1 \%$ of the world's population to experience a once-in-a-century flooding event. The difficulty of attributing the effect of solar geoengineering on any individual event early in a deployment may be even more challenging than it is to attribute an individual event to climate change today, simply because the level of deployment will almost certainly start out smaller. Furthermore, solar geoengineering would be taking place simultaneously with changes in levels of greenhouse gas emissions whose detailed impact remains uncertain.

As noted earlier, a plausible deployment scenario might be to maintain conditions as close as possible to the year in which deployment starts. Such a scenario was simulated by Kravitz et al. (2017), where the background anthropogenic GHG emissions follow a high-end RCP 8.5 scenario (Meinshausen et al., 2011) and $\mathrm{SO}_{2}$ injection is used to maintain 2020 conditions. A few results from that simulation are shown in Figure 3 below, both at a global scale and for the Indian subcontinent (using the South Asia region defined by Giorgi and Francisco, 2000). Solar geoengineering simulations are typically plotted showing the no-geoengineering and geoengineered cases as different colored lines, and often averaged over time or over ensemble members to estimate the forced response. However, society does not have the luxury of experiencing both of those scenarios and determining which one it likes better. Rare events, such as super storms or other environmental extremes, have certain probabilities of occurring in any scenario, and it will only be over decades that one can determine whether the choice to 
deploy or not deploy solar geoengineering might have changed those probabilities. For example, in Figure 3, the change in slope (rate of increase or decrease) for both global mean temperature and global mean precipitation is statistically significant with a $95 \%$ confidence level after 10 years. It takes 20 years for the change in slope of the temperature over South Asia to become statistically significant, and in this model simulation, the change in annual-mean precipitation over that region is still not statistically significant at a $95 \%$ confidence level by 2100. Broadly similar results hold for other regions, with only one region (Greenland) having a statistically significant observable shift in precipitation in under 30 years. Changes in many other variables, such as precipitation averaged over only one season, or the frequency of extreme weather events, may be even more difficult to detect in the presence of natural climate variability.

A long time-scale for detection and attribution is not, in and of itself, a problem. If it is hard to detect a change in some variable, it is hard precisely because the change is small relative to natural variability, and thus that change might not have serious adverse impacts.

However, how should one respond if observations suggest an $80 \%$ chance that some variable has changed in an unanticipated way? Or a 50\% chance? Increased certainty will require waiting for more time to pass. Furthermore, with a sufficiently large range of climate variables being monitored, roughly $5 \%$ will show unusual changes that appear to be statistically significant at a $95 \%$ confidence level. In principle, models can be used to assess the plausibility of a physical connection with the solar geoengineering deployment, rather than simply relying on analysis of time series. However, the entire motivation for looking for possible changes in regional climate arises from concern that the models are imperfect, and so it is the difference from predictions that one is most interested in uncovering through observation.

\section{(insert Figure 3)}

Figure 3. Annual mean temperature and precipitation change relative to 1975-2020 averaged over the globe and over South Asia in a simulation in which stratospheric aerosol geoengineering was initiated in 2020 with the goal of keeping temperatures at 2020 levels in the presence of increasing greenhouse gas concentrations (see Kravitz et al. (2017) for details). In each plot, the black line shows the simulated trajectory, with the star indicating the start of (low-level) deployment. The red dashed line is a 10-year running average of a simulation without geoengineering, indicating what models might tell people would have been happening. The blue line and shaded band are the best fit slope to 1975-2020, and \pm 1 standard deviation of natural variability about this. The change in slope of global mean temperature and precipitation are statistically significant at the $95^{\text {th }}$ percentile after roughly 10 years (using Welch's unequal-variances $t$-test); the regional temperature change over south Asia takes 20 years to show a statistically significant change in trend, while the change in precipitation over this region is not statistically significant in this simulation even by 2100. Note that the unusual response in year 2023 is due to a model error and should be ignored.

\subsection{A continuum of timescales and feedback processes}


Sections 4.1 and 4.2 describe feedback and detection/attribution, which operate on two very different timescales. However, as was alluded to earlier, there is actually a continuum of timescales of decisions surrounding any hypothetical solar geoengineering deployment.

Ultimately the purpose of feedback as discussed here is to manage uncertainties in the climate system by introducing corrections to the best estimated deployment. At any given time, the solar geoengineering deployment is guided by observations and models of the system. This includes projections of long-term changes (e.g., steadily increasing GHG concentrations), as well as short-term system behavior (e.g., is it an El Niño year, or did a climate-altering volcanic eruption just occur?). It might also include new model information that could either directly affect goals (e.g., new information regarding Antarctic ice shelf stability) or suggest better deployment approaches to meet existing goals - indeed model improvements may occur at a timescale in between the fast and slow timescales described in sections 4.1 and 4.2. If at any point any of these components changes, be that the strategic objectives, new climate models, or new information from observations, then the deployment details (e.g., $\mathrm{SO}_{2}$ injection rates or locations) that best meet goals must also change. As was stated earlier, this is a feedback process and is illustrative of the sort of adaptive management approaches that would be necessary to ensure successful deployment.

\section{Implications for governance}

The international community has been able to agree to a target of holding global mean temperature to well below a $2^{\circ} \mathrm{C}$ rise above preindustrial levels. Thus, there is at least a precedent for global agreement on specific quantitative climate goals. One of the challenges with reaching agreement on a "global thermostat" for solar geoengineering is that different regions might differentially benefit or have different desired amounts of warming or cooling. While it might seem that if agreeing on one number is hard, agreeing on multiple goals would be harder still, that may not be true if the ability to independently manage multiple goals means that the distribution of benefits and harms is more uniform. Nonetheless, it will not be possible to design a deployment that can achieve every possible goal in every region of the world, and the trade-offs involved will require the ability to agree on more complex choices than simply a number. (Of course, it is also possible that solar geoengineering might be deployed without broad agreement, but choices on how to deploy would still need to be made.) Deployment goals would be fundamentally political, reflecting not only policy considerations but deeper struggles over the notion and content of an ideal climate, nature vs. artifice, etc. Scientists and engineers can present what is possible and likely or unlikely, but cannot (or should not) decide what objectives to pursue.

Once deployed, there will be a variety of decisions that will need to be made over a wide range of time-scales. Both "slow" and "fast" decisions present interesting challenges for governance. 
The primary challenge in the former may be to avoid action when it is not warranted by the available evidence. Resisting the urge to act while waiting for detection and attribution processes to generate adequate evidence-which may take decades-may pose serious difficulties for decision-makers pressured to respond relatively quickly. Such pressures may derive from short-term political calculations, media hype, civil society campaigns, and many other sources. While uncertainty about the climate response needs to be accepted, and a culture of adaptive management supported, the long time-scales for attribution also create a need to establish processes that would counter the impulse to constantly change the goals of the deployment in response to the latest climate event; there will always be unusual weather events whether solar geoengineering is deployed or not. Slowing down decision-making so that it is synchronized with the pace of monitoring, assessing, and modifying key decisions about deployment will require devising institutional impediments in support of methodical decisionmaking on strategic issues.

The shorter time-scales associated with either managing uncertainty or responding to events such as volcanic eruptions are not well matched to political processes; any delay in operational decisions due to procedural discussions or political posturing will result in larger deviations from the intended goals. Furthermore, political processes may also be ill-suited to these decisions because of the technical knowledge needed to determine the appropriate action. Instead, governance may involve agreeing to the guidelines behind such adjustments and empowering technical experts to make them.

Clearly, decisions about feedback and attribution raise critical questions about the role of technocracy in governing a hypothetical solar geoengineering deployment. Operational decisions will need to be made promptly based on specialized knowledge; these characteristics recommend delegation to experts empowered to perform instrumental adjustments in response to feedback processes and volcanic activity. Strategic decisions made in response to detection and attribution results, or to improvements in knowledge more generally, will rely on expert analysis, which will need to be institutionally insulated from broader debates about the overall purposes, goals, and objectives of solar geoengineering. Both operational decisions and attribution analysis would ideally need to be shielded as much as possible from political interference in order to ensure consistency and predictability, in support of the ultimate goal of climate stability. However, this characterization does not apply to more fundamental decisions about whether to deploy and what goals to pursue, which are primarily political in nature. Maintaining a strict separation between "political" and "technical" decisions is ultimately impossible, given the omnipresence of power dynamics in social relationships including those involving scientists, engineers, and supposedly apolitical technocrats. But modern society offers multiple examples in which such a separation is approximated with positive results. Electrical grids are managed on timescales shorter than a minute by a combination of computerized systems and trained experts at local utilities and regional system operators under the public oversight of subnational, national, and regional regulatory bodies. Economists at central banks, typically coordinating on an international basis, have wide latitude to set 
monetary policy to smooth out multi-year business cycles, but they do so within parameters set by the political system, and are ultimately accountable to elected representatives.

Some commentators have argued that the technical aspects of solar geoengineering make it incompatible with democracy because the inherent complexity would effectively privilege and empower a technocratic elite at the expense of the broader public (Szerszynski et al., 2013, Hulme, 2014). But as Horton et al. (2018) argue, it is not clear that the technical decisions required to implement solar geoengineering would be any more technical than decisions required in a multiplicity of other policy domains, and there are a multiplicity of instances in which technocratic bodies both successfully function within, and are effectively circumscribed by, democratic political systems. Indeed, the examples we cite above were pioneered and refined in modern democracies. In the case of governing deployment of solar geoengineering, expert assessments and advice could be formally channeled to political authorities to assist them in making strategic decisions, while technocrats empowered to make operational decisions could be made substantively accountable to these or other public authorities through institutional means. (To the extent that "pre-deployment" large-scale field tests were conducted following agreement on a conditional decision to deploy, such technocratic arrangements could also support post-research model validation efforts-see MacMartin and Kravitz 2019b.)

To be sure, striking an appropriate balance between expert autonomy and political oversight, particularly on the decadal time-scale required for robust determinations of attribution, will pose serious challenges for any proposal to deploy solar geoengineering. Related issues such as the principal-agent problem regarding delegation will also need to be addressed. Just as geoengineering itself is a design problem, so too is geoengineering governance, and solutions will not be easy. However, solar geoengineering governance also resembles solar geoengineering technology in that it is not binary in character, that is, it is not either democratic or technocratic. Rather, like other forms of global governance, it is likely to entail a mixture of these and other modes of social control, with ample scope for institutional innovation.

In summary, a decision to deploy is more than a simple yes/no, but a responsible deployment decision should also include:

- Definition and agreement on quantitative high-level climate goals. This will likely occur in conjunction with the scientific/engineering process of determining the deployment approach that best meets these goals, evaluating the resulting projected impacts, and explicitly assessing confidence in these projections. Without this definition of goals there is no basis on which to make choices such as where and how much aerosol to inject. Strategic design decisions will be primarily political but also technical in nature. 
- An agreed-upon approach for managing the deployment as a function of time, including observational resources, how the resulting data will be analyzed, how to conduct attribution, and how that feeds into adjustments to the original plan (and potentially also compensation), including rules for how to adjust the solar geoengineering deployment (e.g. $\mathrm{SO}_{2}$ injection rates) across multiple time-scales. Both instrumental operational decisions and detection and attribution analyses will need to be delegated to technical experts, whose organization would need to be specified. Strategic decisions made in response to detection and attribution analyses will need to be slowed down to match the decadal-scale temporal requirements of such analyses and thereby avoid changing the course of a deployment in the absence of evidence supporting such a change.

Governance of solar geoengineering will require international trust, long organizational lifetimes, complex decision-making, and a culture of adaptive management in order to encourage sound decisions about well-intentioned and well-designed climate interventions. Expertise will be essential, and some degree of technocracy will be necessary. By exploring the specifically technical dimensions of decisions about deployment, including the "multi-speed" character of key operational decisions, we hope to have shed more light on the particular tasks experts will be called upon to perform as well as draw out some important implications for governance.

Acknowledgments. We thank Wil Burns for comments on an earlier version of this manuscript. This research was supported in part by the Atkinson Center for a Sustainable Future at Cornell University and by the Indiana University Environmental Resilience Institute and the Prepared for Environmental Change Grand Challenge initiative. The Pacific Northwest National Laboratory is operated for the US Department of Energy by Battelle Memorial Institute under contract DEAC05-76RL01830.

Declaration of interest statement. The authors declare no conflicts of interest

\section{References}

Barrett, S. (2014). Solar geoengineering's brave new world: Thoughts on the governance of an unprecedented technology. Review of Environmental Economics and Policy, 8(2):249. doi:10.1093/reep/reu011.

Bodansky, D. (2013). The who, what, and wherefore of geoengineering governance. Climatic Change, 121:539-551. doi:10.1007/s10584-013-0759-7.

Boucher, O., Kleinschmitt, C., and Myhre, G. (2017). Quasi-additivity of the radiative effects of marine cloud brightening and stratospheric sulfate aerosol injection. Geophys. Res. Lett., 44:11,158-11,165. doi:10.1002/2017GL074647. 
Chris, R. (2015). Systems Thinking for Geoengineering Policy: How to reduce the threat of dangerous climate change by embracing uncertainty and failure. Routledge.

Crutzen, P. J. (2006). Albedo enhancement by stratospheric sulfur injections: A contribution to resolve a policy dilemma? Climatic Change, 77:211-219. doi:10.1007/s10584-006-9101-y.

Dai, Z., Weisenstein, D., and Keith, D. W. (2018). Tailoring meridional and seasonal radiative forcing by sulfate aerosol solar geoengineering. Geophys. Res. Lett. DOI: 10.1002/2017GL076472.

Dykema, J. A., Keith, D. W., Anderson, J. G., and Weisenstein, D. (2014). Stratospheric-controlled perturbation experiment: a small-scale experiment to improve understanding of the risks of solar geoengineering. Phil. Trans. R. Soc. A, 372.

Giorgi, F. and Francisco, R. (2000). Uncertainties in regional climate change prediction: a regional analysis of ensemble simulations with the HADCM2 coupled AOGCM. Climate Dynamics, 16:169-182.

Haywood, J. M., Jones, A., Bellouin, N., and Stephenson, D. (2013). Asymmetric forcing from stratospheric aerosols impacts Sahelian rainfall. Nature Climate Change, pages 660-665. doi:10.1038/nclimate1857.

Herring, S. C., Christidis, N., Hoell, A., Hoerling, M. P., and Stott, P. A. (2019).

Explaining extreme events of 2017 from a climate perspective. Bull. Amer. Meteor. Soc., 100(S1-S117). doi:10.1175/BAMS-ExplainingExtremeEvents2017.1.

Heyward, C, Rayner, S. (2015). Uneasy expertise: Geoengineering, social science, and democracy in the anthropocene. In Policy legitimacy, science and political authority: Knowledge and action in liberal democracies. (eds M Heazle, J Kane), pp. 101-121. London: Earthscan.

Höhne, N., Kuramochi, T., Warnecke, C., Röser, F., Fekete, H., Hagemann, M., ... Gonzales, S. (2017). The Paris Agreement: Resolving the inconsistency between global goals and national contributions. Climate Policy, 17(1), 16-32

Holling, C. S. (1978). Adaptive Environmental Assessment and Management. John Wiley \& Sons.

Horton, J., Parker, A., and Keith, D. (2015). Liability for solar geoengineering: Historical precedents, contemporary innovations, and governance possibilities. N.Y.U. Environmental Law Journal, 22.

Horton, J., Reynolds, J., Buck, H., Callies, D., Schaefer, S., Keith, D., and Rayner, S. (2018). Solar geoengineering and democracy. Global Environmental Politics, 18.

Horton, J. B. and Reynolds, J. L. (2016). The international politics of climate engineering: A review and prospectus for international relations. International Studies Review, 18:438-461. doi:10.1093/isr/viv013.

Horton, JB, Keith, DW. (2019). Multilateral parametric climate risk insurance: A tool to facilitate 
agreement about deployment of solar geoengineering? Clim. Policy 19, 820-826.

(doi:10.1080/14693062.2019.1607716)

Hulme, M. (2014). Can science fix climate change? A case against climate engineering. Cambridge, UK: Polity.

IPCC (2018). Global Warming of 1.5C, an IPCC special report on the impacts of global warming of $1.5 \mathrm{C}$ above pre-industrial levels and related global greenhouse gas emission pathways, in the context of strengthening the global response to the threat of climate change, sustainable development, and efforts to eradicate poverty. IPCC.

Irvine, P., Emanuel, K., He, J., Horowitz, L. W., Vecchi, G., and Keith, D. (2019). Halving warming with idealized solar geoengineering moderates key climate hazards. Nature Climate Change, 9:295-299.

Jarvis, A. and Leedal, D. (2012). The Geoengineering Model Intercomparison Project (GeoMIP): A control perspective. Atm. Sci. Lett., 13:157-163.

Keith, D. W., Duren, R., and MacMartin, D. G. (2014). Field experiments on solar geoengineering: report of a workshop exploring a representative research portfolio. Phil. Trans. R. Soc. A, 372.

Keith, D. W. and Irvine, P. J. (2016). Solar geoengineering could substantially reduce climate risks - A research hypothesis for the next decade. Earth's Future, 4:549-559. doi:10.1002/2016EF000465.

Keith, D. W. and MacMartin, D. G. (2015). A temporary, moderate and responsive scenario for solar geoengineering. Nature Climate Change, 5:201-206. doi:10.1038/nclimate2493.

Keith, D.W., Weisenstein, K.K., Dykema, J.A., and Keutsch F.N. (2016). Stratospheric solar geoengineering without ozone loss? Proc. Nat. Ac. Sciences 113:14910-14

Kirtman, B. et al. (2013). Near-term Climate Change: Projections and Predictability. In Climate Change 2013: The Physical Science Basis. Contribution of Working Group I to the Fifth Assessment Report of the Intergovernmental Panel on Climate Change. Cambridge University Press.

Kravitz, B. et al. (2013). Climate model response from the Geoengineering Model Intercomparison Project (GeoMIP). J. Geophys. Res., 118:8320-8332. doi:10.1002/JGRD.50646.

Kravitz, B., MacMartin, D. G., Leedal, D. T., Rasch, P. J., and Jarvis, A. J. (2014). Explicit feedback and the management of uncertainty in meeting climate objectives with solar geoengineering.

Env. Res. Lett., 9(4).

Kravitz, B., MacMartin, D. G., Mills, M. J., Richter, J. H., Tilmes, S., Lamarque, J.-F., Tribbia, J. J., and Vitt, F. (2017). First simulations of designing stratospheric sulfate aerosol geoengineering to meet multiple simultaneous climate objectives. J. Geophys. Res. A, 122:12,616-12,634. doi:10.1002/2017JD026874. 
Kravitz, B., MacMartin, D. G., Wang, H., and Rasch, P. J. (2016). Geoengineering as a design problem. Earth Systems Dynamics, 7:469-497. doi:10.5194/esd-7-469-2016.

Laakso, A. et al. (2016). Radiative and climate effects of a large volcanic eruption during stratospheric sulfur geoengineering. Atmos. Chem. Phys., 16:305-323. doi:10.5194/acp-16-305-2016.

Latham, J. (1990). Control of global warming? Nature, 347:339-340.

Lewandowsky, S., Cowtan, D., Risbey, J. S., Mann, M. E., Steinman, B. A., Oreskes, N., and Rahmstorf, S. (2018). The 'pause' in global warming in historical context: (II). Comparing models to observations.

Environ. Res. Lett., 13(123007).

Long, J. C. S. and Shepherd, J. G. (2014). The strategic value of geoengineering research. Global Environmental Change, 1.

MacMartin, D. G., Caldeira, K., and Keith, D. W. (2014b). Solar geoengineering to limit rates of change. Phil. Trans. Royal Soc. A, 372.

MacMartin, D. G., Keith, D. W., Kravitz, B., and Caldeira, K. (2013). Management of trade-offs in geoengineering through optimal choice of non-uniform radiative forcing. Nature Climate Change, 3:365368. doi:10.1038/nclimate1722.

MacMartin, D. G. and Kravitz, B. (2019a). Mission-driven research for stratospheric aerosol geoengineering. Proc. National Academy of Sciences, 116(4):1089-1094.

MacMartin, D. G. and B. Kravitz (2019b), The engineering of climate engineering, Annual Review of Control, Robotics, and Autonomous Systems, 2, 2.1-2.23, doi:10.1146/annurev-control-053018-023725.

MacMartin, D. G., Kravitz, B., Keith, D. W., and Jarvis, A. J. (2014a). Dynamics of the coupled humanclimate system resulting from closed-loop control of solar geoengineering. Clim. Dyn., 43(1-2):243-258.

MacMartin, D. G., Kravitz, B., Long, J. C. S., and Rasch, P. J. (2016). Geoengineering with stratospheric aerosols: what don't we know after a decade of research? Earth's Future, 4:543- 548.

MacMartin, D. G., Kravitz, B., and Rasch, P. J. (2015). On solar geoengineering and climate uncertainty. Geophys. Res. Lett., 42:7156-7161. doi:10.1002/2015GL065391.

MacMartin, D. G., Kravitz, B., Tilmes, S., Richter, J. H., Mills, M. J., Lamarque, J.-F., Tribbia, J. J., and Vitt, F. (2017). The climate response to stratospheric aerosol geoengineering can be tailored using multiple injection locations. J. Geophys. Res. A, 122:12,574-12,590. doi:10.1002/2017JD026868.

MacMartin, D. G., Ricke, K. L., and Keith, D. W. (2018). Solar geoengineering as part of an overall strategy for meeting the 1.5C Paris target. Phil. Trans. Royal Soc. A. doi:10.1098/rsta.2016.0454. 
MacMartin, D. G.,Wang, W., Kravitz, B., Tilmes, S., Richter, J., and Mills, M. J. (2019). Timescale for detecting the climate response to stratospheric aerosol geoengineering. J. Geophys. Res. A, 124(3).

MacMynowski, D. G., Keith, D. W., Caldeira, K., and Shin, H.-J. (2011a). Can we test geoengineering? Energy Environ. Sci., 4:5044-5052.

MacMynowski, D. G., Shin, H.-J., and Caldeira, K. (2011b). The frequency response of temperature and precipitation in a climate model. Geophys. Res. Lett., 38. L16711.

Meinshausen, M., Smith, S. J., Calvin, K. V., Daniel, J. S., Kainuma, M. L. T., Lamarque, J.-F., Matsumoto, K., Montzka, S. A., Raper, S. C. B., Riahi, K., Thomson, A. M., Velders, G. J. M., and van Vuuren, D. (2011). The RCP greenhouse gas concentrations and their extension from 1765 to 2300. Climatic Change, 109:213\{241. doi:10.1007/s10584-011-0156-z.

National Academy of Sciences (2015). Climate Intervention: Reflecting Sunlight to Cool Earth. The National Academies Press, 500 Fifth St. NW, Washington DC 20001.

Nicholson, S, Jinnah, S, Gillespie, A. 2018 Solar radiation management: A proposal for immediate polycentric governance. Clim. Policy 18, 322-334.(doi:10.1080/14693062.2017.1400944)

Parson, E. A. (2013). Climate engineering in global climate governance: Implications for participation and linkage. Transnational Environmental Law. doi:10.1017/S2047102513000496.

Parson, E. A. and Ernst, L. N. (2013). International governance of climate engineering. Theoretical Inquiries in Law, 14:307-337.

Pitari, G., Aquila, V., Kravitz, B., Robock, A., Watanabe, S., Cionni, I., Luca, N. D., Genova G. D., Mancini, E., and Tilmes, S. (2014). Stratospheric ozone response to sulfate geoengineering: Results from the Geoengineering Model Intercomparison Project (GeoMIP). J. Geophys. Res. A, 119(5):2629 2653. doi:10.1002/2013JD020566.

Rayner, S., Heyward, C., Kruger, T., Pidgeon, N., Redgwell, C., and Savulescu, J. (2013). The Oxford principles. Climatic Change, 121. doi:10.1007/s10584-012-0675-2.

Reynolds, J. L. (2016). Climate engineering and international law. In Climate Change Law, Elgar Encyclopedia of Environmental Law, Vol. 1. Farber, D. A. and Peeters, M., editors .

Reynolds, J. (2019). Solar geoengineering to reduce climate change: A review of governance proposals, Proc. Royal Soc. A. 475 (2229). Doi:10.1098/rspa.2019.0255.

Ricke, K. L., Granger Morgan, M., and Allen, M. R. (2010). Regional climate response to solar radiation management. Nature Geoscience, 3:537-541. 
Robock, A., Bunzl, M., Kravitz, B., and Stenchikov, G.L. (2010). A test for Geoengineering?, Science, 327, 530-531.

Robock, A., MacMartin, D. G., Duren, R., and Christensen, M. W. (2013). Studying geoengineering with natural and anthropogenic analogs. Climatic Change, 121(3):445-458. doi:10.1007/s10584- 013-0777-5.

Rogelj, J., den Elzen, M., Höhne, N., Fransen, T., Fekete, H., Winkler, H., Schaeffer, R., Sha, F., Riaha, K., and Meinshausen, M. (2016). Paris Agreement climate proposals need a boost to keep warming well below 2C. Nature, 534:631-639. doi:10.1038/nature18307.

Schellnhuber, H. J. and Kropp, J. (1998). Geocybernetics: Controlling a complex dynamical system under uncertainty. Naturwissenschaften, 85. doi:10.1007/s001140050525.

Smith, S.J. and Rasch, P.J. Climatic Change (2013) 121: 487. https://doi.org/10.1007/s10584-0120577-3

Sugiyama, M., Y. Arino, T. Kosugi, A. Kurosawa \& S. Watanabe (2018) Next steps in geoengineering scenario research: limited deployment scenarios and beyond, Climate Policy, 18, 681-689, DOI:10.1080/14693062.2017.1323721.

Szerszynski, B., Kearnes, M., Macnaghten, P., Owen, R., and Stilgoe, J. (2013). Why solar radiation management geoengineering and democracy won't mix. Environment and Planning A, 45(12):28092816. doi:10.1068/a45649.

Talberg, A., S. Thomas, P. Christoff, and D. Karoly, "How geoengineering scenarios frame assumptions and create expectations", Sustainability Science 13:1093-1104, 2018. Doi:10.1007/s11625-018-0527-8

Tilmes, S., Richter, J. H., Mills, M. J., Kravitz, B., MacMartin, D. G., Vitt, F., Tribbia, J. J., and Lamarque, J.F. (2017). Sensitivity of aerosol distribution and climate response to stratospheric $\mathrm{SO}_{2}$ injection locations. J. Geophys. Res. A., 122:12,591-12,615. doi:10.1002/2017JD026888.

Tilmes, S., Richter, J. H., Mills, M. J., Kravitz, B., MacMartin, D. G., Garcia, R.R., Kinnison, D.E., Lamarque, J.-F., Tribbia, J. J., and Vitt, F. (2018). Effects of different stratospheric $\mathrm{SO}_{2}$ injection altitude on stratospheric chemistry and dynamics. J. Geophys. Res. A., doi:10.1002/2017JD028146.

UNFCCC (2015). Adoption of the Paris Agreement. Available at https://unfccc.int/resource/docs/2015/cop21/eng/l09.pdf.

Visioni, D., D.G. MacMartin, B. Kravitz, S. Tilmes, M.J. Mills, J.H. Richter, and M.P. Boudreau, "Seasonal injection strategies for stratospheric aerosol geoengineering", Geophysical Research Letters, 46, 2019. doi:10.1029/2019GL083680

Wigley, T. M. L. (2006). A combined mitigation/geoengineering approach to climate stabilization. Science, 314:452-454. 